Europäische Agrarpolitik

\title{
Exportschlager Hunger
}

\author{
Hunger ist ein Exportschlager aus Deutschland - aus deutschen \\ Tierfabriken. Aus eiweißreichen Futtermitteln Südamerikas \\ entstehen bei uns Fleisch und Milchpulver, die zunehmend als \\ Billigexporte nach Afrika geschifft werden. Dafür ist die euro- \\ päische Agrarpolitik verantwortlich. \\ Von Marita Wiggerthale
}

D

ie Brüsseler Agrarpolitik steckt in jedem Stück Fleisch und in jedem Liter Milch, der bei uns im Einkaufskorb oder auf den Märkten in armen Ländern landet. Wie die Agrarpolitik der Europäischen Union (EU) ausgestaltet wird, hat weitreichende Folgen, nicht nur für Bauern und Bäuerinnen hier und dort, sondern auch für das Bodenleben, die biologische Vielfalt, das Grundwasser, das Klima, die Tierhaltung und die Landschaft in Europa. Die Bilanz ist negativ. Alles spricht dafür und nichts dagegen, die EU-Agrarpolitik grundlegend zu reformieren.

\section{Subventionen umbauen}

Im Papier „Die EU exportiert - die Welt hungert“ zeigt Oxfam auf, warum trotz anerkennenswerter Fortschritte, die EU-Agrarpolitik von entwicklungspolitischer Seite weiter kritisiert wird. Der Umbau des Subventionssystems weg von produktspezifischen Subventionen und Exportsubventionen hin zu einkommensstützenden, produktionsungebundenen Zahlungen an Landwirte hat nicht verhindert, dass neue beziehungsweise steigende Überschüsse bei Schweinefleisch, Geflügelfleisch und Milch entstanden sind (1).

Die Gründe dafür sind niedrigere Futtermittelpreise durch den Abbau der Preisstützung bei Getreide, Investitionsbeihilfen für Stallbauten und die Erhöhung der Milchquoten und damit der Milchmenge insgesamt.
Von 1992 bis 2007 stiegen die Geflügelexporte der EU-15 um knapp 120 Prozent, im Zeitraum 2001-2007 die Schweinefleischexporte um 36 Prozent (Oxfam-Berechnungen gemäß FAO-Statistiken). Entgegen anderslautenden Äußerungen stiegen auch die Exporte in arme Länder. Seit Mitte der 1990er Jahre sind beispielsweise die Geflügelfleischexporte nach Westafrika und die Schweinefleischexporte nach Afrika südlich der Sahara um 500 Prozent gestiegen (EED 2010; EED 2008). Dumpingimporte von Hähnchenflügeln aus der EU haben in Ghana dazu geführt, dass der einheimische Geflügelmarkt komplett zusammengebrochen ist und tausende Geflügelhalter ihre Einkommensquelle verloren haben (EED 2010).

\section{Schutzzölle einführen}

Die EU-Agrarpolitik geht Hand in Hand mit der EU-Handelspolitik. Über Freihandelsabkommen wird in armen Ländern der Zollabbau forciert, um europäischen Schlachthöfen und Molkereien neue Absatzmärkte für die steigenden Überschüsse zu erschließen. Eine Analyse des International Centre for Trade and Sustainable Development (ICTSD) belegt, dass in der Vergangenheit unter anderem Billigimporte von Geflügel, Milch und Schweinefleisch Märkte empfindlich gestört haben (ICTSD 2009). Ein Zollschutz wäre zum Schutz der kleinbäuerlichen Landwirtschaft und für die Ernährungssicherung notwendig gewesen. Aber nur
22 arme Länder haben gemäß dem Agrarabkommen der Welthandelsorganisation genauso wie die EU das Recht, bei Importfluten oder bei Preisverfall einen Schutzzoll zu erheben (2).

Die EU-Agrarpolitik ist darauf ausgerichtet, die Ernährungsindustrie international wettbewerbsfähig zu machen. Deswegen müssen Agrarrohstoffe relativ billig und Erzeugerpreise relativ niedrig sein. Nicht umsonst gehen in der EU 85 Prozent der Direktzahlungen an 17 Prozent der Empfänger, also an leistungsstarke Betriebe. Der Preis für die internationale Wettbewerbsfähigkeit ist jedoch hoch, zu hoch: eine industrialisierte Landwirtschaft, die den Klimawandel anheizt, den Boden schädigt, die biologische Vielfalt reduziert, das Grundwasser mit Nitrat verseucht, das Höfesterben vorantreibt, die Qualität der Lebensmittel mindert und zum Hunger in der Welt beiträgt. Die Zeit ist reif für einen grundlegenden Wandel in der EU-Agrarpolitik!

\section{Anmerkungen}

(1) Die Exportsubventionen wurden von knapp 5,6 Milliarden Euro im Jahr 1999 auf knapp 650 Millionen Euro im Jahr 2009 reduziert.

(2) Informationen im Internet: http://www.wto.org/english/tratop_e/agric_e/ negs_bkgrnd11_ssg_e.htm

\section{Literatur}

EED: Mehr Hähnchenmast in Deutschland - mehr Armut in Afrika? Bonn. 2010.

EED: Pigmeat exports to Sub-Saharan Africa (without South Africa). Bonn. 2008.

ICTSD: Ensuring EU farm policy supports the Millennium Development Goals. Genf 2009.

IUTORIN + KONTAKT

Marita Wiggerthale ist Agrarexpertin bei Oxfam Deutschland.

Marita Wiggerthale, Oxfam Deutschland, Greifswalder Str. 33a, 10405 Berlin. Tel.: +493045306931, E-Mail: mwiggerthale@oxfam.de 


\section{Lizenzhinweis}

Die Beiträge in ÖkologischesWirtschaften werden unter der Creative-Commons-Lizenz "CC 4.0 Attribution Non-Commercial No Derivatives" veröffentlicht. Im Rahmen dieser Lizenz muss der Autor/Urheber stets genannt werden, das Werk darf nicht bearbeitet, abgewandelt oder in anderer Weise verändert und außerdem nicht kommerziell genutzt werden. Die digitale Version des Artikels bleibt für zwei Jahre Abonnent/innen vorbehalten und ist danach im Open Access verfügbar. 